\title{
Copaifera Sabulicola (Leguminosae), uma nOva espécie do CERRADO BRASILEIRO ${ }^{1}$
}

\author{
Jorge Antonio Silva Costa ${ }^{2,4}$ \& Luciano Paganucci de Queiroz ${ }^{3}$
}

\begin{abstract}
RESUMO
(Copaifera sabulicola (Leguminosae), uma nova espécie do cerrado brasileiro) Uma nova espécie de Copaifera (Leguminosae, Caesalpinioideae, Tribo Detarieae) é proposta. Essa nova espécie é conhecida apenas do Brasil, ocorrendo no cerrado do centro-oeste da Bahia e extremo norte de Minas Gerais, e apresenta maior afinidade com Copaifera rondonii F.C. Hoehne. Copaifera sabulicola é descrita, ilustrada e suas afinidades taxonômicas são discutidas.
\end{abstract}

Palavras-chave: Leguminosae, Detarieae, Copaifera, cerrado, Brasil.

\section{Abstract}

(Copaifera sabulicola (Leguminosae), a new species from Brazilian cerrado) A new species of Copaifera (Leguminosae, Caesalpinioideae, Tribe Detarieae) is proposed. This new species is known only from Brazilian Cerrado of central-western Bahia and northern Minas Gerais, and is closely related to Copaifera rondonii F.C. Hoehne. Copaifera sabulicola is described, illustrated, and its relationships with other taxa are discussed.

Key words: Leguminosae, Detarieae, Copaifera, cerrado, Brazil.

\section{INTRODUÇÃo}

Copaifera é um gênero pantropical com cerca de 35 espécies (sensu Lewis et al. 2005). Para o Brasil foram registradas 11 espécies por Bentham (1870) e 18 espécies por Dwyer $(1951,1954)$. Atualmente são registradas cerca de 28 espécies das quais 22 são restritas a este país com maior diversidade na Bahia (12), seguido pelos estados do Mato Grosso (8) e, Amazonas e Pará, ambos com seis espécies. Distribuem-se desde as florestas amazônicas, na Região Norte, até a floresta atlântica e matas ciliares da Região Sul (Dwyer 1951, 1954).

O gênero Copaifera é composto por árvores e arbustos com casca do tronco aromática e é caracterizado pela combinação da folha paripinada com dois ou mais folíolos, flores apétalas, legume com uma semente, esta apresentando um arilo conspícuo. A distinção entre as espécies é feita, principalmente, com base em caracteres das folhas. Esses caracteres envolvem a presença ou não de pontuações nos folíolos bem como o número e a forma dos folíolos. Além disso, são considerados também os caracteres florais como o indumento das sépalas, o comprimento das anteras e o indumento do pistilo (Dwyer 1951, 1954).

De algumas espécies desse gênero se extrai o óleo de copaíba e suas resinas dão resistência e estabilidade em vernizes, tintas e lacas (Lewis 1987). O óleo tem sido investigado na produção de novas drogas, inclusive anti-tumoral (Basile et al. 1988, Ohsaki et al. 1994, Paiva et al. 1998, Cascon \& Gilbert 2000) e é utilizado como cicatrizante e no tratamento de bronquites, hemorróidas e diarréia crônica (Dwyer 1951).

No curso de um tratamento taxonômico das espécies extra-amazônicas de Copaifera, uma nova espécie foi encontrada sendo aqui descrita e ilustrada.

\footnotetext{
Artigo recebido em 08/2006. Aceito para publicação em 12/2006.

${ }^{1}$ Parte da tese de doutorado do primeiro autor desenvolvida no Programa de Pós-Graduação em Botânica da UEFS, Depto. de Ciências Biológicas. Apoio financeiro: CAPES, FAPESB, Flora da Bahia/CNPq

${ }^{2}$ Universidade Federal da Bahia (UFBA), Instituto de Ciências Ambientais e Desenvolvimento Sustentável (ICADS), Colegiado de Ciências Biológicas, Rua Prof. José Seabra, Centro, 47805-100, Barreiras, Bahia, Brasil.

${ }^{3}$ Universidade Estadual de Feira de Santana (UEFS), Departamento de Ciências Biológicas, BR 116 - km 03, Campus Universitário, 44031-460, Feira de Santana, Bahia, Brasil. lqueiroz@uefs.br

${ }^{4}$ Autor para correspondência: jorgeasc@ ufba.br
} 


\section{Resultados e Discussão}

Copaifera sabulicola J.A.S. Costa \& L.P. Queiroz, sp. nov. Tipo: BRASIL. BAHIA: Barreiras, ca. $40 \mathrm{~km} \mathrm{~W}$ de Barreiras na BR 242, 1205'S, 45²2'W, 09.VI.1994, bot. e fl., L.P. de Queiroz \& N.S. Nascimento 4107 (holótipo HUEFS; isótipos CEPEC, IAN, K, MBM, NY, RB, SP).

Fig. 1

Copaifera rondonii F.C. Hoehne affinis sed foliis 2-3-jugatis, sessilibus vel petiolatibus, petiolo nullo vel usque ad $12 \mathrm{~mm}$ longo, foliolis petiolulatis, ellipticis-oblongis, paniculis folium brevioris, floribus pedicelatis diagnoscenda.

Arbusto ou raramente árvore 1-4 (-8) $\mathrm{m}$ alt. Estípulas membranáceas, ovais, glabras, 4-6 × 3-4 mm na porção mais larga. Folhas geralmente, sésseis, pecíolo, quando presente, 1-6 (-12) mm compr., pubérulo a glabro; raque pubérula a glabra, (1-) 1,5-5,5 (-7) cm compr.; folíolos (1-) 2-3 pares (no mesmo espécime), opostos a subopostos (raramente os medianos são alternos), peciolulados, peciólulo 1-2 (-3) mm compr., coriáceos; lâmina $(2,5-) 3-7,5(-8,5) \mathrm{cm}$ compr., elíptico-oblonga, as distais raramente obovais, base simétrica a levemente assimétrica, obtusa ou levemente aguda, ápice obtuso e emarginado, face adaxial glabrescente, face abaxial glabra, nervura principal glabra em ambas as faces; pontuações translúcidas presentes, distribuídas uniformemente na lâmina. Panículas axilares, geralmente menores que as folhas; pedúnculo pubérulo ou glabro, (4-) 6-12 (-13) cm compr.; ramos secundários em $\mathrm{n}^{\mathrm{o}}$ de (6-) 7-12 (-14). Botão floral oval, ápice agudo, $2-4 \times 2-4,5 \mathrm{~mm}$. Flores pediceladas, pedicelo (0,5-) 1-1,5 mm compr.; sépalas 4 , mais ou menos iguais entre si, a mais larga oval-elíptica, 4,5-5 × 2,5-3 mm, as demais elípticas, $4,5-5 \times 2-2,5 \mathrm{~mm}$, todas as sépalas agudas, glabras externamente e hirsutas internamente; estames (8-) 10, filetes (5-) 7-8 mm compr., anteras (1-) 1,2-1,5×1 mm, tecas não apiculadas, mas o conectivo pode formar um pequeno apêndice apical; ovário estipitado, estípite $0,5-0,8 \mathrm{~mm}$ compr., hirsuto, ovário oblongo-orbicular, 1-2 1 0,5-1,5 mm, hirsuto na base e na margem, glabro no centro. Legume curtamente pedicelado, pedicelo 1-2 (-3) mm compr. e estipitado, estípite às vezes pubescente, 2-4 (-8) mm compr.; valvas coriáceas, elíptico-orbiculares, $2-2,6 \times 1,7-2,2 \mathrm{~cm}$, castanhas a nigrescentes quando secas, margens glabras ou raramente pubescentes. Sementes pretas, oblongoorbiculares, $8-10 \times 6-7 \mathrm{~mm}$; arilo alaranjado a vermelho, cobrindo ca. 3/4 da semente.

Parátipos: BRASIL, BAHIA: Barreiras, km 87 Rod. Barreiras-Ibotirama, 10.II.1991, fr., B. A. S. Pereira et al. 1571 (IBGE, NY, RB, UB); Caetité, 14 km N de Caetité em direção a Mamiaçu, 1353'S, $42^{\circ} 27^{\prime}$ W, 12.VI.2005, fr., E. B. Miranda et al. 771 (HUEFS); Correntina, fazenda Jatobá, entre $13^{\circ} \mathrm{e}$ $14^{\circ} \mathrm{S}$, entre $45^{\circ} 45^{\prime}$ e $46^{\circ} 15^{\prime}$, III. 1991 , fr., $L . G$. Viollati et al. 163 (IBGE, K); fazenda Jatobá, entre $13^{\circ}$ e $14^{\circ}$ S, entre $45^{\circ} 45^{\prime}$ e $46^{\circ} 15^{\prime}, 19$.XI.1991, bot. e fl., J. W. B. Machado \& L. G. Viollati 315 (IBGE, $\mathrm{K}, \mathrm{RB}, \mathrm{SFV}) ; 12 \mathrm{~km} \mathrm{~N}$ de Correntina na estrada para Inhaúmas, $13^{\circ} 15^{\prime}$ 'S, 4440'W, 28.IV.1980, fr., R. M. Harley et al. 21886 (CEPEC, K); estrada para Mucambo, $13^{\circ} 18^{\prime} 53^{\prime \prime} \mathrm{S}, 44^{\circ} 38^{\prime} 23^{\prime \prime} \mathrm{W}$, 15.VII.2003, fr., J. Costa et al. 418 (HUEFS); Cocos, estrada para Itaguari, $14^{\circ} 12^{\prime} \mathrm{S}, 4^{\circ} 33^{\prime} \mathrm{W}$ 16.V.2001, fr., F. França et al. 3570 (HUEFS); Mucugê, estrada de Guiné para Palmeiras, $12^{\circ} 45^{\prime}$ S, 41 $30^{\prime} \mathrm{W}, 20 . \mathrm{VI} .2005$, fr., D. Cardoso \& A. A. Conceição 594 (HUEFS); estrada PalmeirasGuiné, 12³9'S, 41'33'W, 18.VI.2005, fr., P. D. Carvalho \& A. A. Conceição 96 (HUEFS); São Desidério, ca. $2 \mathrm{~km}$ da vila Roda Velha, $12^{\circ} 42^{\prime} 20^{\prime \prime} \mathrm{S}$, 45'48'50"W, 7.XI.1997, bot. e fl., M. Aparecida Silva et al. 3504 (IBGE, EAC, MO, NY, RB); a 31 km de Estiva em direção a Roda Velha, 15.X.1989, bot. e fl., B. M. T. Walter et al. 499 (IBGE); estrada de chão entre Roda Velha e Estiva, 7.XI.1997, bot. e fl., R. C. Mendonça et al. 3223 (IBGE, NY); $12^{\circ} 28^{\prime}$ 'S, $45^{\circ} 12^{\prime}$ 'W, 10.IV.1989, fr., A. O. Scariot et al. 497 (IBGE, CEN, INPA, RB); Seabra, em direção a Alagadiço, próximo a BR 242, 12²7'12"S, 41'55'30"W, 21.III.1980, fr., J. E. Brazão 182 (HRB). MINAS GERAIS: Formoso, Parque Nacional Grande Sertão Veredas, 15²5’30"S, 4553'47"W, 2.XII.1997, bot. e fl., $M$. Aparecida Silva et al. 3663 (IBGE, NY, RB). 


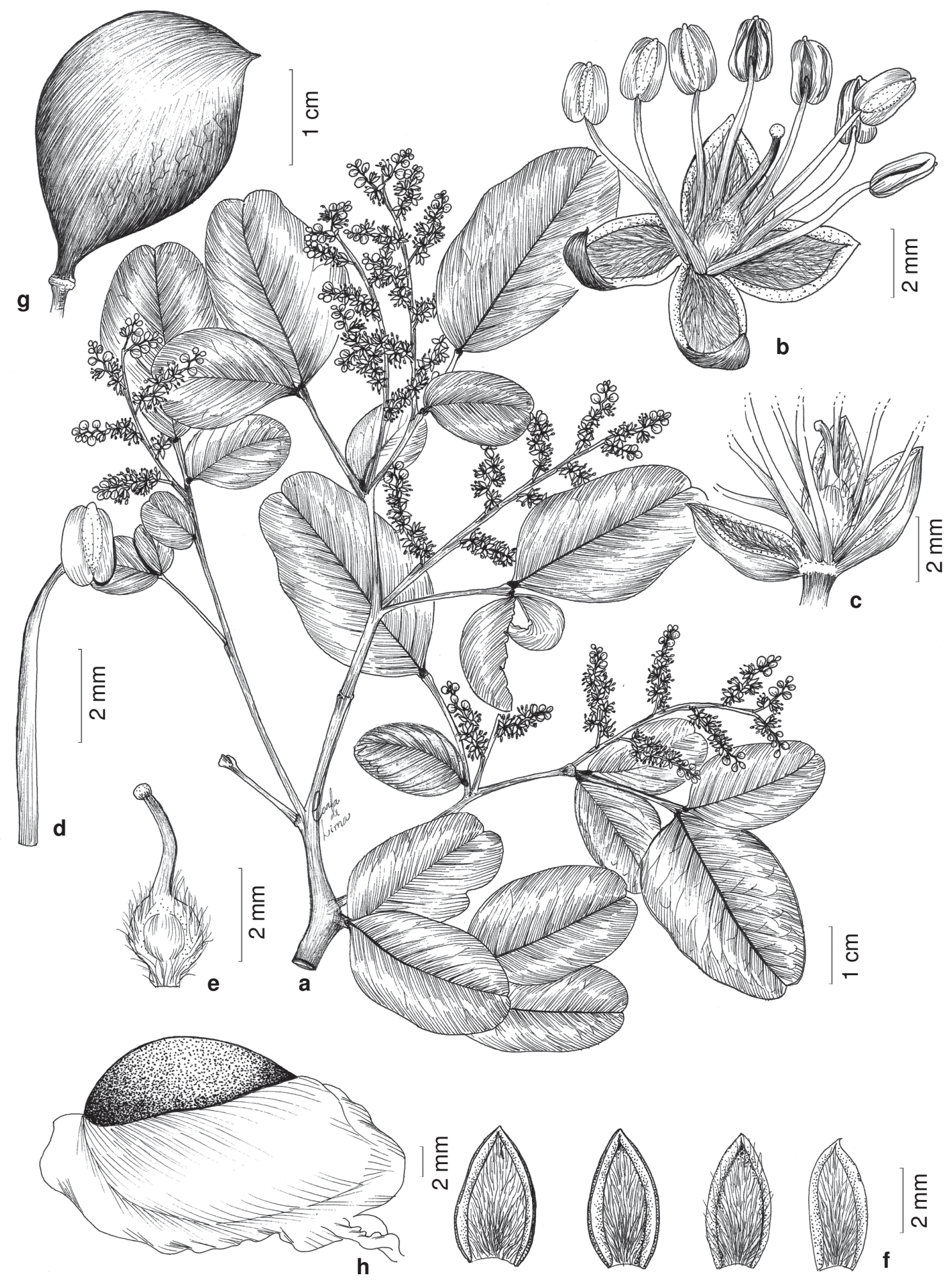

Figura 1 - Copaifera sabulicola J. A. S. Costa \& L. P. Queiroz - a. ramo com inflorescência; b-c. flor; d. estame; e. pistilo; f. sépalas em vista adaxial; g. fruto; h. semente com arilo. (a-f Silva 3504; g-h França 3570) 
Copaifera sabulicola (do Latim: sabulosus $=$ crescendo em locais arenosos) é provavelmente endêmica do cerrado do centro-oeste da Bahia e extremo norte de Minas Gerais, ocorrendo em solo com textura arenosa, especialmente de areias quartzosas brancas. Floresce de outubro a dezembro e frutifica de fevereiro a julho.

Copaifera sabulicola é distinta de todos os demais táxons incluídos em Copaifera por apresentar uma combinação de caracteres tais como, ramos, folhas e folíolos glabros a glabrescentes, raramente pubérulo; folhas geralmente sésseis a pecioladas (no mesmo espécime), folíolos em (1)-2-3 pares com ápice obtuso e emarginado e pontuações translúcidas presentes em toda a lâmina; flores e frutos em geral pedicelados. Esta espécie assemelha-se mais a Copaifera rondonii da qual difere por apresentar folhas geralmente sésseis ou com pecíolo ca. 1-6 (-12) mm compr, folíolos peciolulados (ca. 1-3 mm compr.) e inflorescências menores ou iguais ao tamanho das folhas, enquanto $C$. rondonii apresenta folhas com pecíolo ca. $2 \mathrm{~cm}$ compr., folíolos sésseis e inflorescências duas a três vezes maiores que as folhas.

\section{Agradecimentos}

Agradecemos aos curadores dos herbários aqui citados pelo empréstimo do material durante o desenvolvimento do estudo; à desenhista Carla de Lima pelas ilustrações. Esse projeto foi parcialmente financiado através de auxílio financeiro da FAPESB (processo $\left.n^{\circ} 1431040045982\right)$. Bolsa de doutorado da CAPES ao primeiro autor e bolsa de produtividade em pesquisa do $\mathrm{CNPq}$ ao segundo autor.

\section{REFERÊNCIAS BIBLIOGRÁFICAS}

Bentham, G. 1870. Leguminosae II \& III. Swartzieae, Caesalpinieae, Mimoseae tribus XVII. Cynometreae. In: Martius, C.F.P. von (ed.). Flora brasiliensis 15(2): 239-248.

Basile, A. C.; Sertié, J. A. A.; Freitas, P. C. D. \&Zanini, A.C. 1988. Anti-inflamatory activity of oleoresin from brazilian Copaifera. Journal of Ethnopharmacology 22: 101-109.

Cascon, V. \& Gilbert, B. 2000. Characteriztion of the chemical composition of oleoresins of Copaifera guianensis Desf., Copaifera duckei Dwyer and Copaifera multijuga Hayne. Phytochemistry 55: 773-778.

Dwyer, J. D. 1951. The Central American, West Indian, and South American species of Copaifera (Caesalpinioideae). Brittonia 7(3): 143-172.

Dwyer, J. D. 1954. Further Studies on the New World Species of Copaifera. Bulletin of the Torrey Botanical Club 81(3): 179-187.

Lewis, G. P. 1987. Legumes of Bahia. Royal Botanic Gardens, Kew, 369p.

; G. P.; Schrire, B; Mackinder, B. \& Lock, M. 2005. Legumes of the world. Royal Botanic Gardens, Kew, 577p.

Ohsaki, A.; Yan, L.T.; Ito, S.; Edatsugi, H.; Iwata, D. \& Komoda, Y. 1994. The isolation and in vivo Potent Antitumor Activity of Clerodane Diterpenoid from the Oleoresin of the Brazilian Medicinal Plant, Copaifera langsdorfii Desfon. Bioorganic \& Medicinal Chamistry Letters 4(24): 2889-2892.

Paiva, L. A. F.; Rao, V. S. N.; Gramosa, N. V. \& Silveira, E. R. 1998. Gastroprotective effect of Copaifera langsdorffii oleoresin ou experimental gastric ulcer models in rats. Journal of Ethnopharmacology 62: 73-78. 